\title{
Role of Bone Marrow Cells in the Healing Process of Mouse Experimental Glomerulonephritis
}

\author{
MARI HAYAKAWA, MASAMICHI ISHIZAKI, JUN HAYAKAWA, MAKOTO MIGITA, \\ MUTSUMI MURAKAMI, TAKASHI SHIMADA, AND YOSHITAKA FUKUNAGA
}

Department of Pediatrics [M.H., J.H., M.Mi., M.Mu., Y.F.], Department of Pathology [M.I.], Departments

of Biochemistry and Molecular Biology [T.S.], Nippon Medical School, Tokyo 113-8602, Japan \begin{abstract}
ABST
Recent studies have shown bone marrow (BM) cells to differ-
entiate into a variety of cell types and to thereby participate in the reconstitution of damaged organs. In the present study, we examined the extent to which BM-derived cells are incorporated into glomeruli during recovery from experimentally induced nephritis. To investigate the localization of BM cells in glomeruli, chimeric mice were prepared by transplanting BM cells from green fluorescent protein (GFP) transgenic mice into wild-type mice. Five weeks later, glomerulonephritis was induced by intravenous injection of Habu snake venom. Groups of mice were then killed every few days for $42 \mathrm{~d}$, and harvested kidney samples were subjected to immunohistochemical and immunoelectron microscopic analyses with the aim of detecting the presence of $\operatorname{GFP}(+)$ cells within glomeruli. Chimeric animals injected with Habu venom developed proliferative glomerulonephritis within 1-3 d. The lesion gradually subsided and the glomerular structure returned to normal within $42 \mathrm{~d}$. Consistent with the disease course, large numbers of $\mathrm{GFP}(+)$ cells were
\end{abstract}

present within glomeruli on $\mathrm{d} 1-3$, but most had disappeared by $\mathrm{d} 7$. Nevertheless, some GFP $(+)$ cells did remain within glomeruli showing mesangial proliferative changes, and were found to express thrombomodulin (TM), a specific endothelial cell marker. These GFP-TM-double-positive cells accounted for a mean of 1.31$2.24 \%$ of the total glomerular nuclei from d 7 through d 42 , levels that remained stable for at least $12 \mathrm{mo}$. It thus appears that BM cells can give rise to endothelial cells that participate in the remodeling of glomeruli. (Pediatr Res 58: 323-328, 2005)

Bbbreviations
E-GFP, enhanced green fluorescent protein
GFP, green fluorescent protein
HSV, Habu snake venom
TM, thrombomodulin

The kidney's substantial residual functional capacity is almost entirely due to the approximately one million glomeruli present in each kidney at birth. Postnatal neogenesis of nephron units has never been demonstrated, and renal regenerative ability is believed to be poor. Nevertheless, glomerular reconstruction has been observed in animal models of experimental nephritis, as well as in human glomerulonephritis brought on by steroid therapy (1). Thus, although glomeruli are unable to reproduce lost nephron units, the kidney apparently possesses some regenerative capacity at the cellular level. The mechanism remains unknown, however.

In recent studies, investigators were able to induce differentiation of adult stem or progenitor cells (2) into osteocytes, chondrocytes (3), cardiac myocytes (4), vascular endothelial cells $(5,6)$, hepatic oval cells (7) and glial cells (8-11), but little was discovered about kidney regeneration. Although the relationship between BM stem cells and glomerular mesangial

Received September 25, 2004; accepted November 30, 2004.

Correspondence: Mari Hayakawa, M.D., Department of Pediatrics, Nippon Medical School, 1-1-5 Sendagi, Bunkyo-ku, Tokyo 113-8602, Japan: e-mail: dama@nms.ac.jp

DOI: 10.1203/01.PDR.0000169997.45684.05 cell regeneration has been examined $(12,13)$, the differentiation of progenitor cells into glomerular endothelial cells, which are assumed to be necessary for vascular reconstruction, has not yet been systematically analyzed during regeneration of glomeruli.

The successful isolation of vascular endothelial progenitor cells (5) has made neovascularization using adult stem cells clinically possible $(14,15)$. Although differentiation of glomerular endothelial cells from adult stem cells has not yet been achieved, in earlier studies of the role of endothelial cells in the healing process after induction of experimental nephritis, we showed that endothelial cells were indeed regenerated $(16,17)$. Since then, we have been interested in whether BM-derived cells participate in the regeneration of glomerular endothelial cells. In that regard, Hayakawa et al. (18) produced a BM chimeric mouse by transplanting BM cells from GFP transgenic mice into normal C57Black6 mice. They used the resultant chimeric animals to investigate regeneration of the small intestine, demonstrating them to be a useful model with which to examine the fate of BM stem cells. More recently, we used these GFP chimeric mice to show that BM-derived cells dif- 
ferentiate into cardiac cells (19). In the present study, we used the same model to examine the extent to which BM-derived cells participate in the healing process that follows experimental induction of mesangial proliferative glomerulonephritis, and to assess the ability of BM cells to differentiate into glomerular endothelial cells.

\section{MATERIALS AND METHODS}

Animals. All procedures were performed in accordance with the Nippon Medical School Animal Ethics Committee's regulation and recommendations (Approval number 12-82). The BM transplant recipients were 8-wk-old, male C57BL6/Nj mice purchased from Saitama Experimental Animal Supply (Saitama, Japan). The BM cell donors were E-GFP transgenic mice, originally obtained from Osaka University, Japan (Dr. Okabe) (20). They were also made by $\mathrm{C} 57 \mathrm{BL} 6 / \mathrm{Nj}$ mice. All were maintained in a pathogen-free environment at the Institute of Experimental Animals, Nippon Medical School, Japan.

Bone marrow transplantation. BM transplantation was performed as described previously $(18,19)$. The recipient mice were then killed $1,2,3,4$, or 5 wk later, and the time course of BM reconstruction was examined using flow cytometry.

Flow cytometric analysis. Five weeks after BM transplantation, reconstituted BM and PB cell surface markers were analyzed by flow cytometry (BD Biosciences, San Jose, CA). BM and PB cells were suspended in PBS and labeled with PE-conjugated MAbs (BD PharMingen, San Diego, CA) against Mac-1 (M1/70), Gr1 (RB6-8C5), CD45R/B220 (RA3-6B2), Thy-1.2(30H12), or NK-1.1(PK136), which recognize granulocytes, mature B lymphocytes, T lymphocytes, and natural killer (NK) cells, respectively. BM and PB cells were incubated with each MAb for $30 \mathrm{~min}$ on ice and then washed with PBS. Thereafter, the percentages of GFP-positive cells and cells positive for both GFP and PE were analyzed.

Glomerular injury induced by Habu snake venom. Five weeks after BM transplantation, nephritis was induced in the recipient mice by injecting 2.8 $\mathrm{mg} / \mathrm{kg}$ body weight of lyophilized venom from the Habu pit viper Trimeresurus flavoviridis (HSV; Wako Pure Chemical industries, Osaka, Japan) dissolved in saline via the tail vein. Control mice received saline injections. Groups $(n=5)$ of nephritis-induced and control mice were then killed on d 1, $3,5,7,14,21,28,42$, and 365 after injection of HSV or saline.

Morphologic examination. Mice were killed under ether anesthesia, after which they were perfused with 0.01 M PBS ( $\mathrm{pH}$ 7.4) via the cardiac left ventricle, and the kidneys were removed. Some of the kidneys were fixed for $24 \mathrm{~h}$ in $4 \%$ paraformaldehyde in PBS, embedded in Tissue-Tek O.C.T. Compound (Sakura Finetek, Torrance, CA), frozen in chilled acetone, and stored at $-80^{\circ} \mathrm{C}$ for later immunofluorescent staining. The rest were fixed in $20 \%$ formalin, embedded in paraffin, cut into $3-\mu \mathrm{m}$ sections, and stained with hematoxylin and eosin, periodic acid-Schiff or Masson-trichrome.

Immunohistochemistry. The frozen O.C.T.-embedded tissue blocks were cut into $8-\mu \mathrm{m}$ sections using a cryostat and mounted on Superfrost Plus glass slides (Matsunami Glass, Japan). Some of the sections were observed directly, without immunohistochemical staining. The rest were labeled with polyclonal rabbit anti-rat thrombomodulin (TM) antibody (kindly provided by Dr. D. Stern) diluted 1:2000, which reacts specifically with endothelial cells (21); with a monoclonal rat anti-mouse CD45 antibody diluted 1:400 (BD PharMingen), which reacts with leukocyte common antigen (also known as Ly-5); and with a monoclonal rat anti-mouse F4/80 antigen antibody diluted 1:200 (Cosmo Bio Co., Tokyo, Japan), which reacts with blood monocytes and macrophages derived from BM cells (22). The sections were first incubated with blocking serum (10\% normal goat serum) and then with primary antibody for $1 \mathrm{~h}$ at room temperature, followed by either Texas Red-conjugated goat anti-rabbit or anti-rat IgG (Molecular Probes, Eugene, OR) for $1 \mathrm{~h}$ at room temperature. The labeled sections were mounted with Vectorshield H-1200 (mounting medium with DAPI; Vector Laboratories, Burlingame, CA) and examined using a confocal laser microscope (CLSM, TCS-SP; Leica Lasertechnik, Heidelberg, Germany). For each kidney sample, 20 glomeruli were sequentially examined, and the numbers of cells were counted. Glomerular cross-sections containing only a minor portion of the glomerular tuft $(<20$ discrete capillary segments/cross-section) were not included in the analysis. Cellularity was expressed as the total number of nuclei per glomerular crosssection in tissue sections stained with DAPI. Numbers of GFP-TM-double positive cells per glomerulus were also counted.

Paraffin sections were stained using the indirect immunoperoxidase technique (23). The primary antibody was polyclonal rabbit anti-GFP (Molecular Probe) diluted 1:200; the secondary antibody was biotin-labeled goat antirabbit IgG (DAKO, Glostrup, Denmark) diluted 1:500. Although GFP loses its fluorescence upon deparaffinization, it retains antigenicity, enabling its detailed localization. In similar fashion, we used indirect immunoperoxidase staining with anti-TM antibody to evaluate BM cell differentiation into endothelial cells. As a negative control, primary antibody was replaced with PBS in some samples.

Immunoelectron microscopy. Kidney tissue obtained $42 \mathrm{~d}$ after HSV injection was fixed for $24 \mathrm{~h}$ in $20 \%$ formalin, embedded in Tissue-Tek O.C.T. compound, frozen in chilled acetone, cut into 6- $\mu \mathrm{m}$ sections, and incubated first with anti-GFP antibody overnight at $4^{\circ} \mathrm{C}$, and then with horseradish peroxidase-conjugated goat-rabbit $\operatorname{IgG} \mathrm{F}\left(\mathrm{ab}^{\prime}\right) 2$ (BioSource International, Camarillo, CA) for $2 \mathrm{~h}$ at room temperature. The sections were then fixed for an additional $5 \mathrm{~min}$ in $1 \%$ glutaraldehyde, reacted with $\mathrm{DAB}$ and $\mathrm{H}_{2} \mathrm{O}_{2}$, postfixed in $2 \%$ osmium tetroxide for 60 min, dehydrated in a graded ethanol series, and embedded in Epon 812 resin. Ultrathin sections were observed using a transmission electron microscope (model H 7100; Hitachi Ltd., Tokyo, Japan) at $75 \mathrm{kV}$ with either no counterstaining or slight counterstaining with lead citrate.

Urinary protein. Urine spontaneously voided by each animal was collected for $24 \mathrm{~h}$ in a metabolic cage on the day before sacrifice. Proteinuria was then measured as the ratio of albumin $(\mathrm{mg} / \mathrm{dL})$ to creatinine $(\mathrm{mg} / \mathrm{dL})$ in the collected samples. Urinary albumin was measured with a Behring nephrometer (Dade Behring, Marburg, Germany) using anti-mouse albumin antibody (Valeant Pharmaceuticals, Costa Mesa, CA); creatinine was measured with a Hitachi 7170 autoanalyzer (SRL, Tokyo, Japan).

Statistical analysis. All data are presented as group means \pm SEM. Means were compared using $t$ tests. Values of $p<0.05$ were considered significant.

\section{RESULTS}

Proteinuria. There was no significant difference in urinary albumin (normalized to creatinine levels) between control BMtransplanted and wild-type C57BL6 mice $[0.048 \pm 0.004(n=$ 5 ; 5 wk after BMT) versus $0.043 \pm 0.002(n=5 ; 13$-wk-old mice) $(p<0.01)$ ]. By contrast, urinary protein levels were significantly higher in HSV-injected mice than in control mice during the acute phase of HSV-induced glomerulonephritis (d 1-3 after injection) (Fig. 1). No difference in the levels of

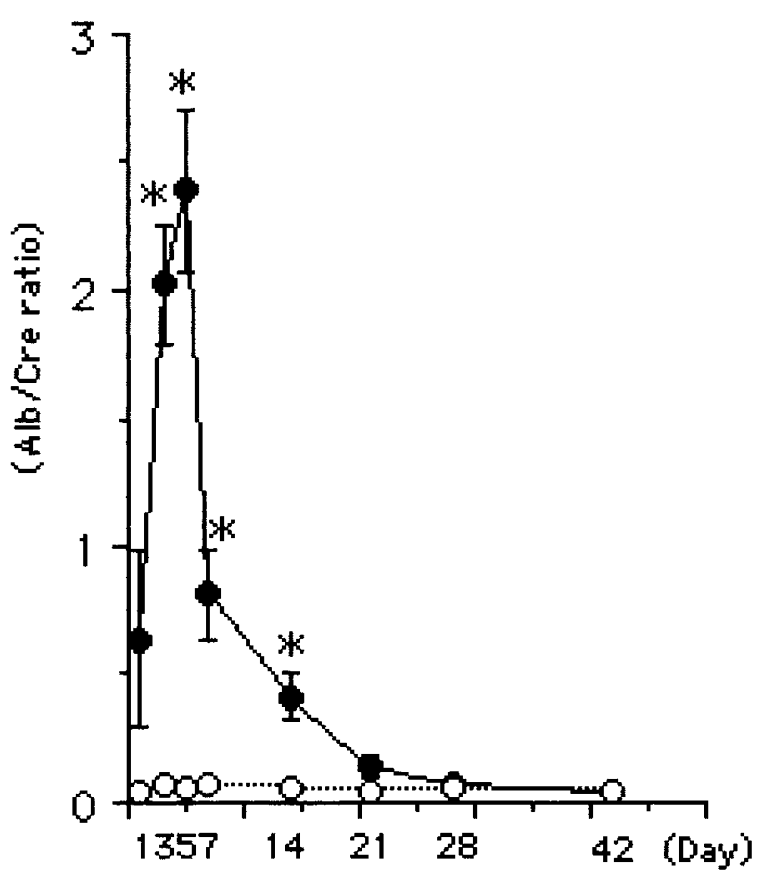

Figure 1. Urinary protein excretion in HSV-induced nephritis. Levels of urinary albumin (normalized to the levels of creatinine) in HSV-treated mice were significantly higher than control from d 3 to $d 14$. Data are expressed as means $\pm \mathrm{SEM} ;{ }^{*} p<0.01$. (Closed and open circles represent the numbers in experimental and control mice.) 
urinary protein was detected after $21 \mathrm{~d}$, however, suggesting that although HSV induced glomerulonephritis, there was full recovery of renal function.

Evaluation of BM cells after transplantation. After BM transplantation, mice were killed weekly for $5 \mathrm{wk}$, and GFP expression in BM and PB cells was evaluated by flow cytometry. We found that within $1 \mathrm{wk}$ after $\mathrm{BM}$ transplantation, donor-derived $\mathrm{GFP}(+)$ cells accounted for $95.70 \%$ of BM cells; within $5 \mathrm{wk}, 99.50 \%$ of PB cells had been replaced with donor-derived $\mathrm{GFP}(+)$ cells. These mice were therefore deemed to be a successful chimeric model, as described previously $(18,19)$.

In addition, many GFP-positive PB cells (96.2\% 1 mo after BMT) differentiated into Mac-1/Gr1 (23.4 土 0.9\%), CD45R/B220 (36.4 土 $1.2 \%)$, Thy-1,2 (53.6 $\pm 2.1 \%)$, and NK-1.1(4.7 $\pm 0.1 \%)$ lineages, and the proportion of each lineage in recipient $\mathrm{PB}$ was similar to that seen before BM transplantation.

Morphologic assessment of HSV-induced glomerular lesions. The pathologic glomerular alterations observed after injection of HSV were in general agreement with previously published reports (24-26), so after preliminary experimentation to determine the appropriate dosage, we used the effects of $2.8 \mathrm{mg} / \mathrm{kg}$ of $\mathrm{HSV}$ as our glomerulonephritis model in subsequent experiments.

The structural changes that occurred during the healing process after induction of glomerulonephritis are shown in Figure 2. After HSV administration, $30 \%$ of the glomeruli exhibited capillary dilatation and mesangiolytic ballooning during the acute phase $(\mathrm{d}$ 1-3). By d 7, mesangial proliferative changes, which were accompanied by mesangial expansion, were observed. These proliferative changes were diminished by d 28, however. And by $\mathrm{d}$ 42 , no sclerosis or adhesion was present in any of the glomeruli, and Masson-trichrome staining revealed no interstitial fibrosis (Fig. 2f). Glomeruli from control animals showed no noteworthy histologic changes during the experimental period.

The same nephritis course was seen in the frozen sections, in which numerous $\mathrm{GFP}(+)$ cells were observed within glomeruli exhibiting mesangiolytic ballooning during the acute phase (Fig. 3, $a$ and $d$ ). The GFP $(+)$ cells were comprised of platelets and inflammatory cells, which were stained by anti-CD45 or anti-F4/80 antibody. By d 7, when healing of the loop structure of the glomeruli was evident, the numbers of $\operatorname{GFP}(+)$ cells within the glomeruli had declined (Fig. 3, $b$ and $e$ ), whereas the numbers had increased in the interstitium surrounding the glomerular lesion. Numbers of interstitial GFP(+) cells continued to increase until d 14, after which they gradually declined until d 42 (Fig. 3, $c$ and $f$ ).

Regeneration of endothelial cells during this time course was examined by immunohistochemical labeling of TM (Fig. 4). During the acute phase, GFP-TM-double-positive cells were rarely detected within the glomeruli. By d 7, however, the numbers of GFP-TM-double-positive cells-measured as the ratio to the total number of nuclei within glomeruli-were significantly higher than in control mice (Fig. 5). Still, the proportion of double-positive cells was very low, accounting for only $2.24 \%$ of the nuclei present. Moreover, 12 mo after HSV injection, GFPTM-double-positive cells accounted for $2.11 \pm 0.13 \%$ of nuclei, which was not significantly different from the level seen at $42 \mathrm{~d}$. And almost all GFP(+)TM(-) cells in glomerulus were positively stained by both anti-CD45 and anti-F4/80 antigen (Fig. 6).
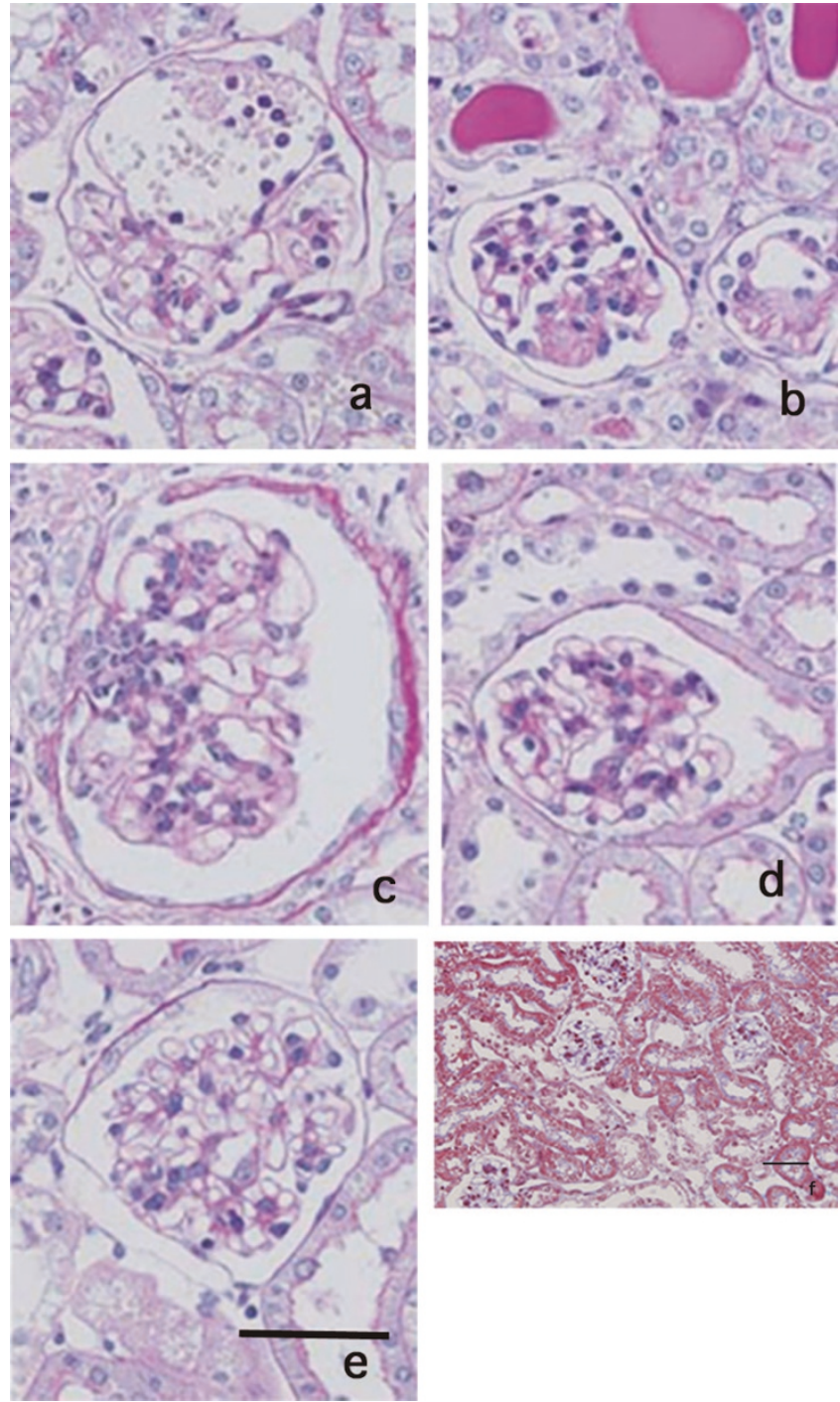

Figure 2. The course of nephritis after HSV administration. (a) D 1: Mice were oliguric, with $30 \%$ of glomeruli exhibiting capillary dilatation and ballooning, resulting in microaneurysms filled with platelet aggregates, leukocytes, erythrocytes, and plasma proteins. (b) D 3: The microaneurysms developed into proliferative lesions. The mice exhibited diuresis, and proteinuria developed in renal tubules. (c) D 7: Levels of infiltrating inflammatory cells were lower in the glomerular lesion, revealing mesangial proliferative changes. (d) D 28: Proliferative changes were diminished; expansion of the mesangial matrix was detectable. (e) D 42: Normal glomerular structure was restored. $(f)$ D 42: Masson-trichrome staining revealed no interstitial fibrosis. ( $a-$ $e)$ :periodic acid-Schiff stain; bar $=200 \mu \mathrm{m}(a-e)$; bar $=200 \mu \mathrm{m}(f)$.

Similarly, some GFP( + ) cells in the interstitium were also stained by anti-CD45 and anti-F4/80 antigen, though many cells were not stained by one antibody or the other.

Immunohistochemical analysis of paraffin sections. To investigate the localization of GFP in greater detail, paraffin sections were stained with anti-GFP antibody. Seven days after induction of nephritis, $\operatorname{GFP}(+)$ cells were evident in the area of the endothelial cells. By d 42, the $\operatorname{GFP}(+)$ cells were limited to the area of the endothelial cells and were no longer detected in the epithelial or mesangial areas (Fig. 7).

Immunoelectron microscopy. The finding that after the HSV-induced nephritis had healed (d 42) GFP was present mainly in glomerular endothelial cells was confirmed by im- 


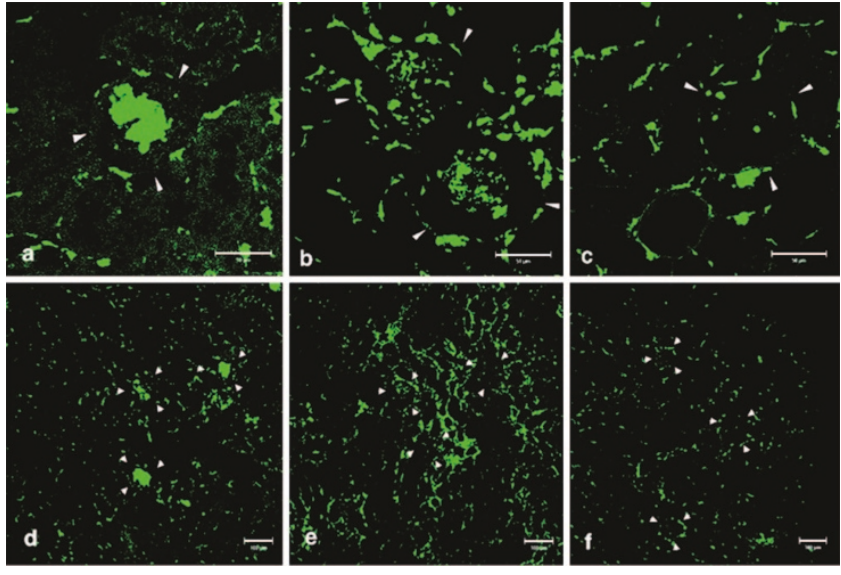

Figure 3. The course of nephritis observed by confocal laser microscope. ( $a$, d) D: Numerous $\operatorname{GFP}(+)$ cells were detected within glomeruli (arrowheads); by contrast, numbers in the interstitium were not elevated. $(b, e) \mathrm{D}$ : Numbers of GFP $(+)$ cells within glomeruli (arrowheads) were diminished, though some were detected in glomeruli along the restored loop structure. Numerous $\mathrm{GFP}(+)$ cells were now detected in the interstitium surrounding the restored glomeruli. ( $c, f) \mathrm{D} 42$ : Numbers of both glomerular (arrowheads) and interstitial GFP $(+)$ cells were reduced. Bar $=50 \mu \mathrm{m}(a-c)$; bar $=100 \mu \mathrm{m}(d-f)$.

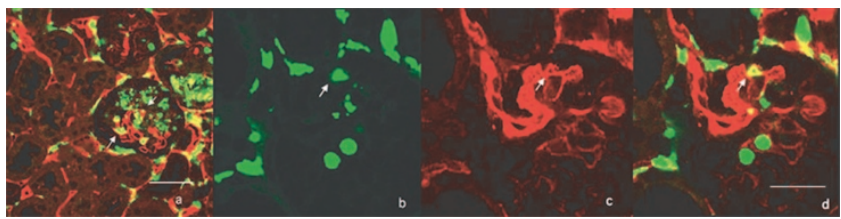

Figure 4. Confocal laser microscopic analysis of frozen sections stained with Texas Red-conjugated thrombomodulin. (a) D 7 double exposure. (b-d) D 7 zoom of glomeruli: (b) GFP, (c) Texas Red, (d) double exposure (arrow: GFP and TM double exposure). Bar $=50 \mu \mathrm{m}(a) ;$ bar $=15 \mu \mathrm{m}(b-d)$.
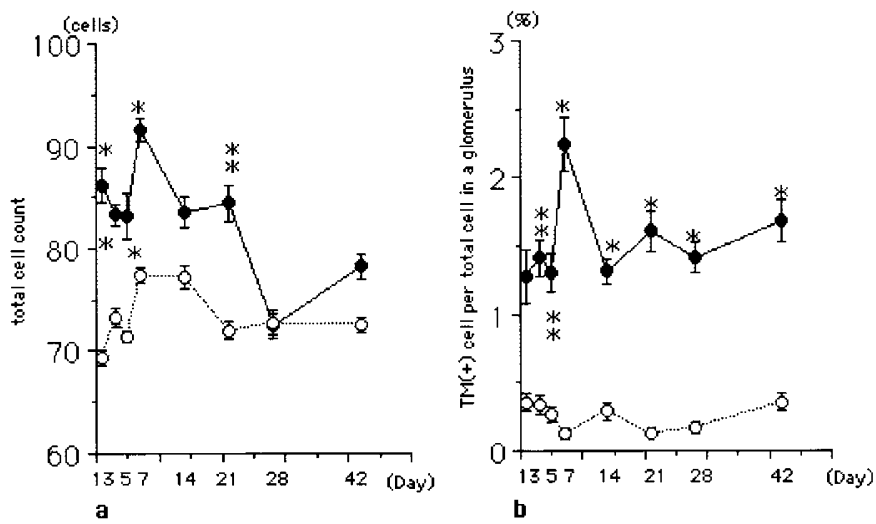

Figure 5. Numbers of ( $a$ ) total cells in the glomerulus (DAPI positive) and ( $b$ ) GFP-TM-double-positive cells per total cells in the glomerulus. Closed and open circles represent the number in experimental $(n=5)$ and control mice $(n=5)$ at the indicated times. Values are expressed as means \pm SEM; ${ }^{*} p<$ $0.01, * * p<0.05 v s$. control. Data were derived from the analysis of 20 glomerular cross-sections.

munoelectron microscopy using an anti-GFP antibody (Fig. 8). Not all endothelial cells were GFP(+), however, and GFP(+) blood cells shed into the lumen were also detected within the glomerulus shown. Outside the glomerulus, $\operatorname{GFP}(+)$ cells were observed among the endothelial cells of the blood vessel and migratory mononuclear cells (data not shown).

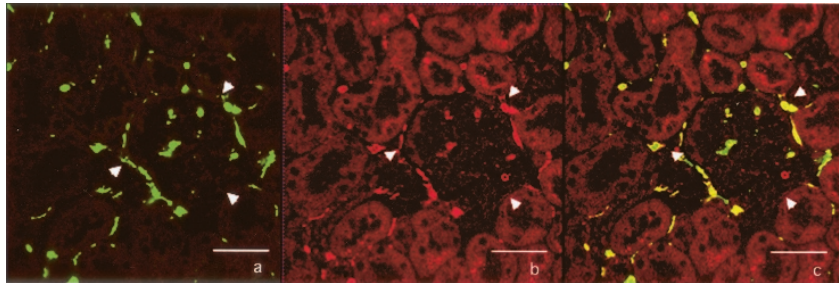

Figure 6. Confocal laser microscopic analysis of frozen sections stained with Texas Red-conjugated CD45 and F4/80. The section was stained by anti-CD45 and anti-F4/80 antigen at the same time. Almost all the glomerular GFP $(+)$ cells were stained double positive for CD45 and F4/80 in day 28 after the nephritis. (a) GFP, (b) Texas Red, (c) double exposure. Bar $=50 \mu \mathrm{m}$.

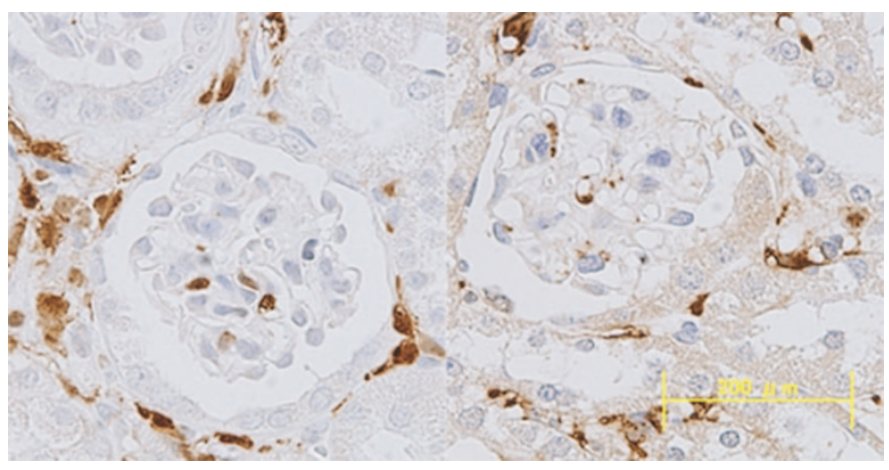

Figure 7. Immunohistochemical analysis of a paraffin section stained with anti-GFP antibody. We detected GFP(+) cells in the area of endothelial cells $42 \mathrm{~d}$ after HSV administration.

\section{DISCUSSION}

We have shown that BM-derived cells differentiate into glomerular endothelial cells during the glomerular healing process after the induction of mouse Habu-venom nephritis. Kitamura et al. (16) previously investigated the regeneration of endothelial cells in a rat model of Habu-venom glomerulonephritis and found that the number of endothelial cells in the glomeruli peaked on $\mathrm{d}$ 7 , as the numbers of infiltrating inflammatory cells in the mesangiolytic ballooning lesion declined revealing mesangial proliferative changes. $\mathrm{TM}(+)$ endothelial cells accounted for $25 \%$ of the total glomerular nuclei. In the present study, we found that in our murine model the number of cells positive for both GFP and TM within glomeruli also peaked on $\mathrm{d} 7$, but that the frequency of these cells was very low, indicating that regeneration of endothelial cells cannot be accounted for by BM-derived cells alone. We suggest, therefore, that the regenerated cells were derived primarily from intrinsic glomerular cell components, with BM-derived cells playing a role in endothelial regeneration. This suggestion is supported by the observed long-term survival of BM-derived endothelial cells.

The role of BM cells in glomerular regeneration has also been investigated by Ito et al. (13) using a chimeric rat model. That study showed that, after Thy-1 nephritis, BM-derived cells participate in glomerular regeneration by differentiating into mesangial cells. About the same time. Cornacchia et al. (27) produced a BM-transplanted mouse chimera from which they harvested glomerular cells that were subsequently separated by microdissection and placed in culture. Among the cultured cells, they identified both mesangial and endo- 


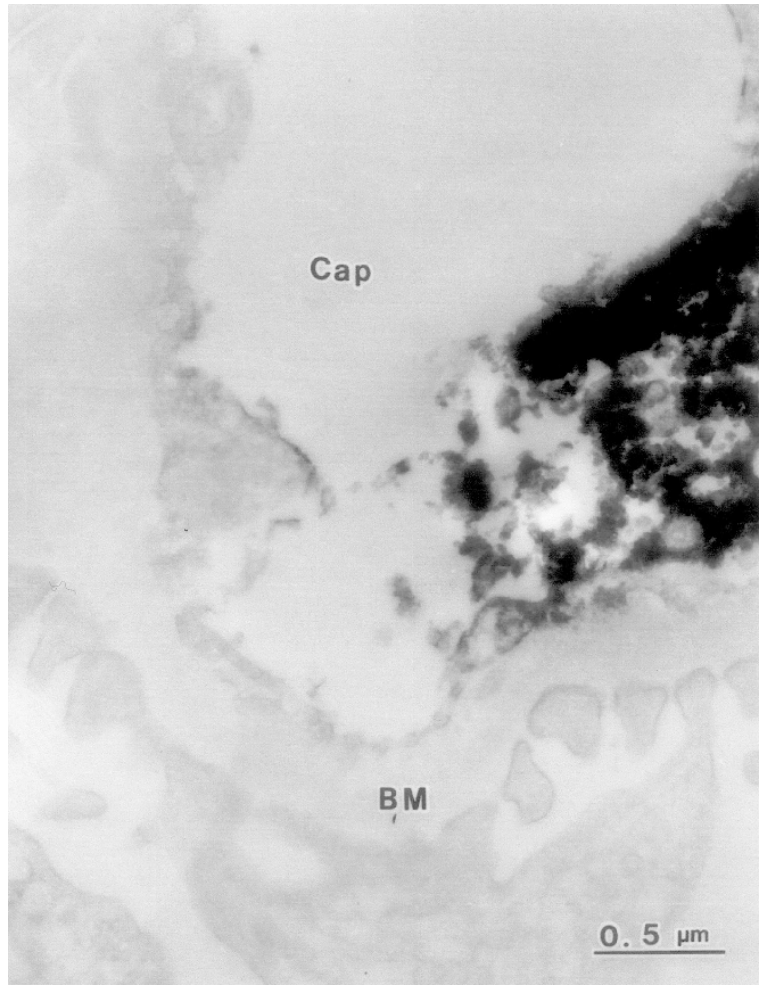

Figure 8. Immunoelectron micrograph shows the distribution of GFP on d 42 after HSV injection. Note the presence of $\operatorname{GFP}(+)$ cell in the endothelial cell area.

thelial cells derived from the transplanted BM cells. Similarly, Rookmaaker et al. (28) showed that BM cells regenerate both glomerular mesangial and endothelial cells in a rat nephritis model. It is noteworthy, moreover, that they detected the regeneration in rat tissue sections. In the present study, we also detected differentiation of BM cells into glomerular endothelial cells in tissue sections; however, our results differ from those of Rookmaaker and colleagues in several important ways. First, we used a mouse model instead of a rat model. Second, we succeeded in quantifying BM-derived endothelial cells by evaluating the relation between BM cells and glomerular endothelial cells. We suggest that the number of regenerated cells in each glomerulus varies with the magnitude of the lesion and the locus of the glomerulus selected (i.e. surface of the cortex or around the medulla). We therefore considered the number of GFP-TM-double positive cells with respect to the total number of DAPI-stained nuclei per glomerular cross-section. Furthermore, in our experiment, regeneration of glomerular endothelial cells using BM-derived cells was also detected in control mice without nephritis. For that reason, we also compared regeneration of endothelial cells in mice with and without nephritis. Our findings show that over the time course of the experiment the number of regenerated endothelial cells was significantly higher among mice with nephritis than among healthy control mice. Third, our GFP-transplanted mouse model has an advantage over other models in that both the recipient and the donor of the transplant are of the same strain, which means that we did not have to consider the immunologic response to heterologous antigen. Moreover, we were able to observe the behavior of BM-derived cells without immunologic marking. Finally, we used immunoelectron microscopy with an anti-GFP antibody, which enable us to investi- gate the BM-derived cells in more detail than Rookmaaker et al. (28) were able to.

We think that whether or not endothelial cells are able to proliferate is the most important consideration in glomerulonephritis because that is a key determinant of the progression of glomerular sclerosis. In that regard, the groups of Kitamura (16) and Iruela-Arispe (29) reported that glomeruli are capable of healing after injury when endothelial cells show proliferative responses. In the same vein, Shimizu et al. (17) reported that incomplete capillary repair leads to sclerotic scar lesions in damaged glomeruli. We therefore focused mainly on endothelial regeneration and were able to unequivocally demonstrate differentiation of BM-derived glomerular endothelial cells using both quantitative and electron microscopic analyses.

It was recently reported that, in vitro, BM cells can adopt the phenotype of other cells through spontaneous cell fusion (30). Our experiments do not exclude the possibility that $\operatorname{GFP}(+)$ endothelial cells may have arisen via fusion of recipient endothelial cells and GFP(+) donor BM cells. On the other hand, we would expect the frequency of in vivo cell fusion to be very low, if there is any at all, and transdifferentiation of BM cells into endothelial cells is well documented in other experimental systems (28). Still, further genetic analysis to determine the origin of each $\mathrm{GFP}(+)$ cell would seem appropriate.

Another potential concern is that the act of BM transplantation itself causes renal damage. In the present study, however, transplanted mice exhibited no histologic changes detectable under light microscopy, and proteinuria was not increased. In addition, Gobe et al. (31) showed that many neonatal rat kidney cells become apoptotic during the first day after irradiation. We therefore investigated cell apoptosis of irradiated mouse kidney using 2-d old neonatal (6 Gy) and 8-wk-old adult (10 Gy) C57BL6 mice. We found large numbers of apoptotic cells in neonatal mouse kidneys $5 \mathrm{~h}$ after radiation, but we rarely detected apoptotic cells in adult mice kidneys at any time up to $24 \mathrm{~h}$ after irradiation (unpublished data). For this reason, we do not believe our model was influenced by 10 Gy radiation.

The future application of these findings may include clarifying the genetics behind the migration of BM cells and their differentiation into endothelial cells. In addition, because these cells remain in the glomerulus once they have differentiated, it may be possible to use BM cells transfected with genes necessary for the treatment of the glomerulus as a gene delivery system. And, ultimately, a full understanding of how differentiation of BM derived cells is regulated in the kidney may mean regeneration of the organ will eventually be possible.

Acknowledgments. The authors thank Dr. David Stern and Dr. Yukio Yuzawa, Columbia University, New York, NY, for providing the anti-TM antibody; Ms. Kyoko Wakamatsu, Mr. Takashi Arai, and Ms. Arimi Ishikawa for expert technical assistance; Dr. Shigeru Sato, Ms. Akiko Adachi, and Mr. Yoshihiro Sasaki for technical support of electron microscopy; and Dr. Akira Shimizu, Dr. Ryuji Ohashi, Dr. Hiroshi Kitamura, Dr. Yukinari Masuda, Dr. Yuichi Sugisaki, Dr. Yu Fukuda, and Dr. Nobuaki Yamanaka for helpful discussions and advices. 


\section{REFERENCES}

1. McIntyre CW, Fluck RJ, Lambie SH 2001 Steroid and cyclophosphamide therapy for IgA nephropathy associated with crescenteric change: an effective treatment. Clin Nephrol 56:193-198

2. Petersen BE, Terada N 2001 Stem cells: a journey into a new frontier. J Am Soc Nephrol 12:1773-1780

3. Pittenger MF, Mackay AM, Beck SC, Jaiswal RK, Douglas R, Mosca JD, Moorman MA, Simonetti DW, Craig S, Marshak DR 1999 Multilineage potential of adult human mesenchymal stem cells. Science 284:143-147

4. Orlic D, Kajstura J, Chimenti S, Limana F, Jakoniuk I, Quaini F, Nadal-Ginard B, Bodine DM, Leri A, Anversa P 2001 Mobilized bone marrow cells repair the infarcted heart, improving function and survival. Proc Natl Acad Sci U S A 98:10344-10349

5. Asahara T, Murohara T, Sullivan A, Silver M, van der Zee R, Li T, Witzenbichler B, Schatteman G, Isner JM 1997 Isolation of putative progenitor endothelial cells for angiogenesis. Science 275:964-967

6. Kalka C, Masuda H, Takahashi T, Kalka-Moll WM, Silver M, Kearney M, Li T, Isner JM, Asahara T 2000 Transplantation of ex vivo expanded endothelial progenitor cells for therapeutic neovascularization. Proc Natl Acad Sci U S A 97:3422-3427

7. Lagasse E, Connors H, Al-Dhalimy M, Reitsma M, Dohse M, Osborne L, Wang X, Finegold M, Weissman IL, Grompe M 2000 Purified hematopoietic stem cells can differentiate into hepatocytes in vivo. Nat Med 6:1229-1234

8. Bjornson CR, Rietze RL, Reynolds BA, Magli MC, Vescovi AL 1999 Turning brain into blood: a hematopoietic fate adopted by adult neural stem cells in vivo. Science 283:534-537

9. Kopen GC, Prockop DJ, Phinney DG 1999 Marrow stromal cells migrate throughout forebrain and cerebellum, and they differentiate into astrocytes after injection into neonatal mouse brains. Proc Natl Acad Sci U S A 96:10711-10716

10. Mezey E, Chandross KJ, Harta G, Maki RA, McKercher SR 2000 Turning blood into brain: cells bearing neuronal antigens generated in vivo from bone marrow. Science 290:1779-1782

11. Nakano K, Migita M, Mochizuki H, Shimada T 2001 Differentiation of transplanted bone marrow cells in the adult mouse brain. Transplantation 71:1735-1740

12. Imasawa $T$, Utsunomiya $Y$, Kawamura $T$, Zhong $Y$, Nagasawa R, Okabe $M$, Maruyama N, Hosoya T, Ohno T 2001 The potential of bone marrow-derived cells to differentiate to glomerular mesangial cells. J Am Soc Nephrol 12:1401-1409

13. Ito T, Suzuki A, Imai E, Okabe M, Hori M 2001 Bone marrow is a reservoir of repopulating mesangial cells during glomerular remodeling. J Am Soc Nephrol 12:2625-2635

14. Isner JM, Asahara T 1999 Angiogenesis and vasculogenesis as therapeutic strategies for postnatal neovascularization. J Clin Invest 103:1231-1236

15. Carmeliet P, Luttun A 2001 The emerging role of the bone marrow-derived stem cells in (therapeutic) angiogenesis. Thromb Haemost 86:289-297

16. Kitamura H, Sugisaki Y, Yamanaka N 1995 Endothelial regeneration during the repair process following Habu-snake venom induced glomerular injury. Virchows Arch 427:195-204
17. Shimizu A, Masuda Y, Kitamura H, Ishizaki M, Sugisaki Y, Yamanaka N 1998 Recovery of damaged glomerular capillary network with endothelial cell apoptosis in experimental proliferative glomerulonephritis. Nephron 79:206-214

18. Hayakawa J, Migita M, Ueda T, Shimada T, Fukunaga Y 2003 Generation of a chimeric mouse reconstituted with green fluorescent protein-positive bone marrow cells: a useful model for studying the behavior of bone marrow cells in regeneration in vivo. Int J Hematol 77:456-462

19. Kuramochi Y, Fukazawa R, Migita M, Hayakawa J, Hayashida M, Uchikoba Y, Fukumi D, Shimada T, Ogawa S 2003 Cardiomyocyte regeneration from circulating bone marrow cells in mice. Pediatr Res 54:319-325

20. Okabe M, Ikawa M, Kominami K, Nakanishi T, Nishimune Y 1997 'Green mice' as a source of ubiquitous green cells. FEBS Lett 407:313-319

21. Horvat R, Palade GE 1993 Thrombomodulin and thrombin localization on the vascular endothelium; their internalization and transcytosis by plasmalemmal vesicles. Eur J Cell Biol 61:299-313

22. Brittan M, Hunt T, Jeffery R, Poulsom R, Forbes SJ, Hodivala-Dilke K, Goldman J, Alison MR, Wright NA 2002 Bone marrow derivation of pericryptal myofibroblasts in the mouse and human small intestine and colon. Gut 50:752-757

23. Hsu SM, Raine L, Fanger H 1981 Use of avidin-biotin-peroxidase complex (ABC) in immunoperoxidase techniques: a comparison between $\mathrm{ABC}$ and unlabeled antibody (PAP) procedures. J Histochem Cytochem 29:577-580

24. Cattell V, Bradfield JW 1977 Focal mesangial proliferative glomerulonephritis in the rat caused by habu snake venom. A morphologic study. Am J Pathol 87:511-524

25. Eitner F, Westerhuis R, Burg M, Weinhold B, Grone HJ, Ostendorf T, Ruther U, Koch KM, Rees AJ, Floege J 1997 Role of interleukin-6 in mediating mesangial cell proliferation and matrix production in vivo. Kidney Int 51:69-78

26. Nakao N, Hiraiwa N, Yoshiki A, Ike F, Kusakabe M 1998 Tenascin-C promotes healing of Habu-snake venom-induced glomerulonephritis: studies in knockout congenic mice and in culture. Am J Pathol 152:1237-1245

27. Cornacchia F, Fornoni A, Plati AR, Thomas A, Wang Y, Inverardi L, Striker LJ, Striker GE 2001 Glomerulosclerosis is transmitted by bone marrow-derived mesangial cell progenitors. J Clin Invest 108:1649-1656

28. Rookmaaker MB, Smits AM, Tolboom H, Van'tWout K, Martens AC, Goldschmeding R, Joles JA, Van Zonneveld AJ, Grone HJ, Rabelink TJ, Varharr MC 2003 Bone-marrow-derived cells contribute to glomerular endothelial repair in experimental glomerulonephritis Am J Pathol 163:553-562

29. Iruela-Arispe L, Gordon K, Hugo C, Duijvestijn A M, Claffey K P, Reilly M, Couser W G, Alpers C E, Johnson R J 1995 Participation of glomerular endothelial cells in the capillary repair of glomerulonephritis Am J Pathol 147:1715-1727

30. Terada N, Hamazaki T, Oka M, Hoki M, Mastalerz DM, Nakano Y, Mayer EM, Morel L, Petersen BE, Scott EW 2002 Bone marrow cells adopt the phenotype of other cells by spontaneous cell fusion Nature 416:542-545

31. Gobe GC, Axelsen RA, Harmon BV, Allan DJ 1988 Cell death by apoptosis following X-irradiation of the foetal and neonatal rat kidney Int J Radiat Biol $54: 567-576$ 